\title{
ATUAÇÃO DE PROFISSIONAIS DE SAÚDE EM DOAÇÃO DE ÓRGÃOS NA PERSPECTIVA DO FAMILIAR: UMA ANÁLISE PROBLEMATIZADORA
}

\author{
Elton Carlos de Almeida \\ Sonia Maria Villela Bueno² \\ Vanessa Antoniassi Denardi Baldissera ${ }^{3}$
}

DE ALMEIDA, E. C.; BUENO, S. M. V.; BALDISSERA, V. A. D. Atuação de profissionais de saúde em doação de órgãos na perspectiva do familiar: uma análise problematizadora. Arq. Cienc. Saúde UNIPAR, Umuarama, v. 19, n. 2, p, 139-145, maio/ago. 2015

\begin{abstract}
RESUMO: Objetivou-se conhecer a atuação profissional no processo de doação de órgãos na perspectiva do familiar. Realizou-se metassíntese qualitativa de estudos brasileiros publicados entre 2001 a janeiro de 2015 veiculados na PubMed, SCOPUS, CINAHL, EMBASE, Web of Science, Science Direct, LILACS, BDENF. Resultando em 273 trabalhos, que após levantamento efetivo e exaustivos, resultaram sete artigos, os quais foram selecionados e submetidos à leitura criteriosa quanto à metodologia utilizada, sujeitos investigados, resultados obtidos e conclusões. Processaram-se sínteses, construídas da análise temática dos resultados, permitindo a definição de três categorias: a) Falta de confiança na atuação profissional; b) Atuação profissional sem compreensão e acolhimento no momento familiar; c) Falta de informação à família pelo profissional, desmembrada nas subcategorias: c.1) Falta de informação à família pelo profissional referente à possível morte encefálica; c.2) Falta de informação à família pelo profissional referente aos trâmites pós-doação. Depreendeu-se da complexidade de ações do processo de doação de órgãos, envolvendo: burocracia, demora, desgaste e cansaço, necessitando de investimentos na formação dos profissionais para melhoraria da atuação, considerada incipiente pelos familiares.
\end{abstract}

PALAVRAS-CHAVE: Doação dirigida de tecido; Obtenção de tecidos e órgãos; Família; Atitude do pessoal de saúde.

\section{HEALTH PROFESSIONALS ACTING IN ORGAN DONATIONS IN THE FAMILY PERSPECTIVE: A PROBLEM-BASED ANALYSIS}

\begin{abstract}
Our aim in this study was to evaluate the opinion of the family about the professional performance during the process of organs donation (POD). In order to do so, a qualitative meta-synthesis from Brazilian studies between 2001 and January 2013 was performed. Data were collected from (i) Pubmed, (ii) SCOPUS, (iii) CINAHL, (iv) EMBASE, (v) Web of Science, (vi) Science Direct, (vii) LILACS, and (viii) BDENF. A total of seven out of 273 papers were considered relevant. These were carefully read in order to assess methodology, subjects investigated, results and conclusions. The analyzes have allowed the definition of three categories: (a) lack of confidence in the professional, (b) professional performance without understanding of relatives emotional state, (c) professional apathy in providing information to the family. The last category was subdivided into (i) lack of information about a possible brain death, and (ii) subsequent procedures about POD. These studies revealed the complexity of actions in the POD, particularly on bureaucracy, delay, family fatigue and wear. Thus, it can be concluded that it is necessary to invest efforts on training the professional involved in the POD to protect the psychological state of the family.
\end{abstract}

KEYWORDS: Directed Tissue Donation; Tissue and Organ Procurement; Family; Attitude of Health Personnel.

\section{Introdução}

A história de doação/transplante de órgãos e tecidos humanos vem rompendo barreiras e enfrentando desafios, embora de forma incipiente por diversas décadas. Todavia, vem conquistando resultados significativos, demonstrando a evolução científica e tecnológica aplicada ao setor. No Brasil, os transplantes sem seres humanos tiveram início em 1964, evoluindo consideravelmente, no tocante às técnicas, resultados, variedades de órgãos transplantados e números de procedimentos realizados (COELHO; MATIAS; GODOY, 2003).

Diante desta evolução, adveio a Lei dos Transplantes (Lei n. 9.434, de 04/02/1997), modificada pela Lei n. 10.211 (de 23/03/2001), regulamentada pelo Decreto Presidencial n. 2.268 (de 30/06/1997), que dispõe sobre a remoção de órgãos, tecidos e partes do corpo humano, para fins de doação/transplante e tratamento. Por esse decreto, foi criado no âmbito do Ministério da Saúde - MS, o Sistema Nacional de Transplante - SNT, instituindo na época, uma curva ascendente de resultados promissores, no que diz respeito aos transplantes para a história brasileira.

Nos últimos cinco anos, triplicaram os recursos do Ministério da Saúde, destinados aos programas de apoio. Contudo, diante de toda evolução e investimentos, apenas $30 \%$ da demanda teórica estimada, é atendida e 16 estados, com 60 milhões de habitantes, não realizam o procedimento, de forma regular. E no primeiro semestre de 2011, notou-se uma pequena queda na taxa de potenciais doadores notificados $(2,2 \%)$ (GARCIA, 2011).

No entanto, observa-se que, ao longo dos tempos, o número de doações tem aumentado, ainda que sem redução da lista de espera, cabendo reflexão acerca das causas que dificultam esse processo. Diversos são os motivos pelos quais afetam a doação de órgãos, ressaltando-se a recusa dos familiares e a não notificação de possíveis doadores. Assim, vale considerar a importância da atuação profissional no que diz respeito à abordagem familiar, momento decisivo para

DOI: https://doi.org/10.25110/arqsaude.v19i2.2015.5434

"Extraído da dissertação "Doação de Órgãos e visão da família sobre atuação dos profissionais neste processo: revisão sistemática da literatura brasileira", Escola de Enfermagem de Ribeirão Preto da Universidade de São Paulo, 2011.

${ }^{1}$ Enfermeiro. Mestrando em Ciências pelo Departamento de Enfermagem Psiquiátrica e Ciências Humanas - DPCH da Escola de Enfermagem de Ribeirão Preto - EERP/USP. Membro Efetivo do Grupo de Pesquisa CAESOS. Ribeirão Preto, SP, Brasil. eltoncarlos@usp.br

${ }^{2}$ Psicopedagoga. Profa. Dra. Livre Docente do Departamento de Enfermagem Psiquiátrica e Ciências Humanas - DPCH da Escola de Enfermagem de Ribeirão Preto - EERP/USP. Presidente do Grupo de Pesquisa CAESOS-DPCH-EERP/USP. Ribeirão Preto, SP, Brasil smvbueno@eerp.usp.br ${ }^{3}$ Enfermeira. Dra. em Ciências. Professora do DEN/UEM. End: Av. Colombo 5790, Maringá-PR. E-mail: vanessadenardi@hotmail.com 
que se possa dar continuidade ao processo de captação de órgãos, já que o sucesso da prestação da assistência à família e ao paciente se faz com os profissionais da saúde que necessariamente, devam encontrar-se preparados, na questão de conhecimentos e emoções, entre outros aspectos (CINQUE; BIANCHI, 2010)

Destaca-se, ainda, que até mesmo os profissionais encontram dificuldades de lidar com a temática, pois para que se possa dar início ao processo doação/transplante faz-se necessário assumir a finitude da vida - fato temido pelo ser humano (SANTOS; BUENO, 2010). Essa questão torna-se relevante quando se considera que a morte pode refletir como um fracasso e, assim, evidenciar a inadequação e limitações do profissional da área da saúde. Além do fato em que o profissional depara-se com sua impotência na realização de suas atividades. A perda de um ente familiar o leva à ciência de sua finitude e, muitas vezes, acaba sendo alvo da indignação dos familiares diante da morte do paciente (SILVA; SILVA, 2007).

Assim, é indiscutível a necessidade de compreender a atuação dos profissionais na perspectiva dos próprios familiares envolvidos, por meio da visão da família nuclear ou do responsável legal, com o intuito de entender as dificuldades que permeiam esse processo. Tal intento pode levar à proposição de estratégias educativas eficazes para a formação profissional. A busca por respostas na literatura científica poderia auxiliar na compreensão dessa realidade.

Assim, o presente estudo objetivou analisar o aspecto problematizador da atuação do profissional de saúde no processo de doação de órgãos no território brasileiro, a partir da perspectiva do familiar que vivenciou essa prática.

\section{Metodologia}

Tratou-se de um estudo descritivo-analítico, fundamentado na metassíntese qualitativa da literatura científica, a partir da revisão sistemática, discutido sob a luz do referencial problematizador de Paulo Freire.

Para tanto, foi necessário explorar, recolher, organizar, sintetizar e compartilhar, por meio da revisão sistemática da literatura, os resultados de artigos primários referentes à percepção dos familiares em relação à atuação dos profissionais de saúde no processo de doação de órgãos no território brasileiro.

A pesquisa delineou-se, portanto, a partir da questão norteadora: Qual a atuação dos profissionais de saúde envolvidos no processo de doação de órgãos no território brasileiro na perspectiva dos familiares que vivenciaram essa prática?

O percurso da metassíntese qualitativa, norteada pela revisão sistemática, utilizou técnica científica objetiva, eficiente e reprodutível. Desenvolveu-se por meio da estratégia PICo, sendo "P" família, "I" ao fenômeno de interesse, que no estudo e foco, refere-se a atuação profissional e o "Co" ao desfecho, o resultado que se esperava encontrar (JBI, 2008), que nesse estudo referiu-se à percepção do familiar do doador quanto à atuação do profissional de saúde nesse processo.

Foram considerados artigos de estudos qualitativos de pesquisas primárias realizadas no Brasil, independente do país de publicação e do desfecho da doação de órgãos, publicados no período de 2001 até janeiro de 2015. O recorte temporal a partir de 2001 foi adotado por embasar-se na Lei $\mathrm{n}^{\mathrm{o}} 10.211 / 2001$ que definiu ser a família a única responsável pelo destino do paciente com morte encefálica, sobretudo quanto à decisão pela doação de órgãos e tecidos.

Estabeleceu-se, como critérios para inclusão de artigos, os estudos que abordavam a temática doação de órgãos e que evidenciavam a percepção dos familiares responsáveis pelo potencial doador de órgão quanto à atuação dos profissionais envolvidos nesse processo. Quanto à característica etária desses familiares, somente foram incluídos os artigos que tratassem da percepção de familiar adulto, pois esses se enquadram nas prerrogativas legais, para autorização de doação de órgãos, exposto no Art. 4 da Lei n. 10.211/2001.

Foram excluídos artigos que tratassem da atuação profissional, na perspectiva dos próprios, tais como enfermeiros, médicos, psicólogos dentre outros. Também se excluíram os artigos que focassem na percepção de receptores de órgãos e/ou de seus familiares quanto à atuação profissional junto aos transplantados. Os artigos que não contivessem no título os Descritores em Ciências da Saúde (DeCS) da Biblioteca Virtual em Saúde (BVS), Medical Subject Headings $(\mathrm{MeSH})$, as palavras-chave e/ou termos livres que indicassem a potencialidade de encontrar a descrição da percepção da família no processo de doação de órgãos, foram excluídos. Essa forma de exclusão, entretanto, seguiu os seguintes passos: leitura do título, leitura do resumo e leitura do texto na íntegra (BARROSO et al., 2008), garantindo que fossem excluídos os artigos que realmente não responderiam a questão norteadora dessa pesquisa.

As buscas foram realizadas no portal PubMed e nas bases de dados SCOPUS, CINAHL, EMBASE, Web of Science, Science Direct, LILACS e BDENF. Os descritores foram definidos por meio dos Descritores em Ciências da Saúde (Decs) da Biblioteca Virtual em Saúde (BVS), e do Medical Subject Headings (MeSH), por meio do National Center for Biotechnology Information (NCBI). Em cada base de dados, foram necessários descritores específicos. Porém, iniciou-se com: doação de órgãos; doação dirigida de tecido; transplantes de órgãos; obtenção de tecidos e órgãos; educação em saúde; família; pessoal de saúde; atitude do pessoal de saúde.

Após a seleção dos artigos que atendiam os critérios de inclusão e exclusão estabelecidos, foram realizadas novas buscas utilizando os descritores presentes nos trabalhos selecionados e que não haviam sido mencionados nas buscas anteriores, assim como, foram analisadas as referências de cada estudo, no intuito de aprofundar as buscas.

Depois de todo este processo, sete artigos foram considerados pertinentes para o estudo e selecionados para a presente pesquisa. A etapa seguinte, foi analisá-los criticamente, utilizando o Teste de Confiabilidade JBI QARI Critical Appraisal Checklist for Interpretive \& Critical Research.

Buscando a integração interpretativa de achados qualitativos pertinente à metassíntese qualitativa (LOPES; FRACOLLI, 2008), adotou-se o referencial problematizador de Freire, a partir da definição das situações-limites (FREIRE, 1987), expostas na forma de categorias analíticas.

Cumpre esclarecer que situações-limites, na concepção crítica de Freire, são todos os obstáculos que se colocam, para homens e mulheres, como freios para sua emancipação. É, pois, condição indispensável, o seu desvelamento 
para que, superadas, as situações-limites se transformem em possibilidades de novas práticas. O movimento de pensar sobre as ações e remodelá-las, revela o que Freire denominou de processo 'ação-reflexão-ação', exprimindo o caminho autêntico para as mudanças (FREIRE, 1987). Nesse estudo, as situações-limites desveladas, permitiram problematizar a atuação dos profissionais de saúde no processo de doação de órgãos no território brasileiro (ação), permitindo discutir essa prática (reflexão) e apontar caminhos para a mudança (ação), concretizando o caminho da 'ação-reflexão-ação' freireana.

\section{Resultados e Discussões}

O processo de análise e interpretação dos artigos selecionados por esse estudo, permitiu que se definissem as situações-limites que envolvem a atuação dos profissionais de saúde no processo de doação de órgãos, no território brasileiro, apontadas como categorias analíticas: 1) Há falta de confiança da família na atuação do profissional de saúde envolvido no processo de doação de órgãos; 2) A prática profissional no processo de doação de órgãos se dá sem a adequada compreensão do momento e acolhimento familiar; 3) O profissional de saúde no processo de doação de órgãos não informa adequadamente a família: 3.1) Sobre a possível morte encefálica; 3.2) Sobre os trâmites legais e operacionais pós-doação. Tais categorias passarão a ser discutidas.

$\mathrm{O}$ aspecto problematizador desta realidade, recai sobre a formação profissional de saúde, no entorno do processo de doação de órgãos, no que se refere à sua prática cotidiana. Para melhor discutir esses achados no seu aspecto problematizador, apresentam-se as situações-limites encontradas, descritas na forma de categorias analíticas:

\section{Categoria Analítica 1 - Há falta de confiança da família na atuação do profissional de saúde envolvido no proces- so de doação de órgãos}

Desvelamos que, na percepção familiar, existe desconfiança quanto ao diagnóstico de morte ou sua antecipação, sobretudo para a comercialização de órgãos:

[...] há crença de que a morte do parente possa ser antecipada ou induzida objetivando a doação dos órgãos[...] (WS01)

[...] o comentário das pessoas de que médicos matam para retirar os órgãos[...] (LL01)

[...] desconfiança na assistência e o medo do comércio de órgãos dificulta o processo[...] (WS02)

Estes receios se fazem presentes também, em outros países. Estudos realizados no Japão e na França, demonstram que a escassez de transplantes com órgãos obtidos de doadores cadáveres, se deve à falta de confiança no sistema médico japonês e francês (CANTAROVICH, 2005; KUCHI; TANAKA, 2003).

Esse processo, por si só, tem uma tendência de ser interpretado com olhar capitalista, momento em que surgem desconfianças referentes à verdadeira intenção da abordagem familiar. Há por um lado, um sentimento altruísta dos profissionais e por outro lado, ocasionalmente, se desconfia de haver a intenção mercenária visando lucros e benefícios próprios. Isto é mais do que complexo, pois, o que demanda necessariamente, é a ética.

Dessa forma, vale repensar se há esclarecimentos suficientes à população sobre a temática, pois, quando a família conhece o desejo do paciente, fica mais fácil de aceitar a doação (ROZA, et al., 2009). E para que ocorram campanhas que esclareçam a população, é importante que os profissionais sejam preparados para esse fim.

Não se pode perder de vista, as questões que se têm constatado, já que há que se reconhecer os inúmeros avanços tecnológicos e a elaboração de novos medicamentos que auxiliam na diminuição do número de rejeição de órgãos transplantados. Tais fatos transformaram, de forma significante, o processo de doação/transplante de órgãos, o que possibilitou a superação da fase experimental e tornou-se uma opção terapêutica. Porém, toda essa evolução, só pode ser considerada eficaz, após tal efetivação, e para oficializar esse procedimento, pressupõe que a família venha proceder sua autorização, à medida que confia na atuação dos profissionais envolvidos, nesse processo.

Estudos mostram que o consentimento familiar é a maior limitação no sucesso de transplante (BRYCE, et al., 2005). Destarte, no intuito de eliminar essa limitação, diz que é de suma importância um atendimento adequado visando não só a doação, mas também, oferecer assistência que envolva a família em todo processo, com o intuito de obter resultados satisfatórios. Isto pode ser evidenciado no recorte, a seguir:

... a assistência prestada durante a internação do paciente é satisfatória, quando observa que o atendimento é adequado e que os profissionais estão empenhados no tratamento... quando há crença na falta de assistência adequada ou o descontentamento com o atendimento prestado, os familiares ficam revoltados e desejam expressar essa revolta fazendo a reclamação no próprio hospital... (LLO1)

Vale ressaltar que torna-se, extremamente, necessária, a integração entre os profissionais que atuam nessa área, objetivando oferecer ao possível doador de órgão, assim como, aos familiares, assistência digna. Isso pode aproximar os familiares da verdadeira intenção dos profissionais frente à solicitação para doação. E possivelmente, diminuir a falta de confiança que os familiares demonstram em relação à atuação profissional, a qual deve ser realizada com base numa constante comunicação, o que iria viabilizar o aumento de informações ao familiar referente o estado do paciente, o que resultaria na credibilidade do serviço.

... a credibilidade na equipe de saúde é uma condição determinante no grau de incerteza dos familiares... (LLO2).

Todos os seres humanos sabem ou têm noção da sua finitude e que o fim devido, é inevitável. A temática morte acaba se tornando tema, extremamente, delicado quando é abordado em associação à questão da doação de órgãos ${ }^{(10)}$. Diante disso, é importante que o profissional tenha a certeza da ocorrência da morte encefálica, à seguir, com a abordagem para doação de órgãos (RECH; FILHO, 2007). Isto pode evitar na atitude da família, a desconfiança em relação à con- 
duta ética do profissional.

Portanto, é necessário que todos os esforços sejam destinados à manutenção da vida do paciente. E que esse não seja encarado como um potencial doador, antes de serem realizados todos os exames necessários, visando aumentar a credibilidade na conduta ética dos profissionais envolvidos.

\section{Categoria Analítica 2 - Atuação profissional sem compre- ensão e acolhimento familiar}

Na presente categoria, depreende-se da importância de acolher e compreender o familiar frente à perda de seu ente querido, isso, durante todo o processo de doação/transplante de órgãos, possibilitando assim, a reflexão e o diálogo entre os familiares e profissionais, facilitando a decisão mais adequada para o familiar, pois, respeitar e compreender o momento do outro é mais importante do que doação em si.

No entanto, vale destacar que, as questões relativas ao binômio doação-transplante por si só, são de extrema complexidade, iniciando com a identificação e manutenção dos potenciais doadores. Nesse processo, é de suma importância permitir que o familiar acompanhe todos os trâmites realizados ao ente querido, no intuito de esclarecer todo o processo. De maneira geral, as pessoas não têm a informação necessária para que se possa tomar a decisão consciente referente à doação de órgãos, o que pode resultar na negativa familiar.

Neste processo, é visível o sentido de preocupação na conduta da família. Sendo assim, ela merece atenção e cuidado especial, no que tange à orientação adequada frente à todo procedimento exigido. Para tanto, faz-se mister refletir sobre a possibilidade do familiar ter um fácil acesso à UTI, assim como, acompanhar todos os exames realizados ao paciente até o momento, e ter esclarecimentos referentes a todos os procedimentos que o paciente será submetido. Esse contato e essa comunicação aberta, democrática, dialógica e de horizontalidade, facilita um melhor entrosamento entre o profissional e o familiar (FREIRE, 1987; BUENO, 2009).

Nesta oportunidade, o profissional deve oferecer um suporte emocional ao familiar, diante das incertezas em que se encontra, priorizando não só a obtenção dos órgãos, mas, uma assistência humanizada tanto para a família quanto ao paciente. Então, os familiares necessitam do envolvimento profissional durante o período de internação. Assim, podemos constatar esses dados nos recortes seguintes, afirmando que:

... na perspectiva de alguns, a falta de atenção à familia, desestimula o processo de doação... (LLO3)

... as Famílias que não permitem a doação, referem-se a uma abordagem precoce e sem envolvimento...(LL04)

Dessa forma, vale ressaltar que a abordagem para doação de órgãos deve respeitar o momento da perda, de maneira sensível, esclarecedora, respeitosa e acompanhada de comunicação e linguagem clara para o familiar. É muito importante também, oferecer conforto diante à morte e ao mesmo tempo, tentar transformar esse desalento em um ato de solidariedade. Nesse intuito, o suporte emocional aliado à informação sobre o processo pode ser crucial para a atitude de doação (SIMINOFF et al., 2007).
No momento da internação, é importante que o profissional possa oferecer toda informação sobre o estado clínico do paciente. Estudo desenvolvido no Canadá demonstrou entre seus resultados que, as famílias necessitam de informação e suporte emocional na fase crítica de internação de seu ente querido (PELLETIER, 1992).

$\mathrm{O}$ apoio deve ser oferecido à família, independente da manifestação contrária à doação, pois o profissional deve se comportar todo o tempo, de forma ética e acolhedora, sensibilizando-se com a situação de sofrimento e dor dos familiares.

... a falta de sensibilidade da equipe é um fator que adiciona sofrimento, quando a família percebe que o único interesse do profissional que está cuidando do potencial doador é a doação de órgãos. O resultado para doação acaba sendo negativo... (WSO2)

Diante o exposto, pode-se dizer que, a influência positiva neste sentido não é aquela que leva a família a autorizar a doação, mas sim, a que conduz a família a uma trajetória de recuperação do sofrimento, seja ela autorizando, ou não, a doação de órgãos. E em vez de oferecer somente, a possibilidade de doação e depois abandonar a família, pode-se extrair o seu melhor e estimular à superação do caos (BOUSSO, 2008).

Pode-se dizer então que, para que este processo ocorra com qualidade, o profissional precisa encontrar um ponto de equilíbrio para lidar com conflitos pessoais que a confrontação com a morte do outro lhe impõe, o que nos leva a questionar como estão sendo preparados esses profissionais para atuarem com tais questões emocionais.

Os profissionais envolvidos no cuidado de cada paciente e suas famílias, também pode levá-los a sentirem desconforto e medo, favorecendo o seu distanciamento no processo de doação, para não sofrerem com essas experiências (SANTOS; BUENO, 2010). Isto é, o motivo que se leva a refletir sobre a importância do preparo efetivo desses profissionais, para atuarem adequadamente, e de forma positiva, nesse processo.

\section{Categoria Analítica 3 - Falta de informação pelo profis- sional}

Conforme pode ser observado no recorte a seguir, a habilidade de comunicação é muito importante no processo de doação de órgãos, facilitando assim, a compreensão dos familiares referente ao estado de saúde do paciente, por meio da explicação de seus exames clínicos e laboratoriais, aproximação da temática morte encefálica, principalmente, no momento da abordagem familiar para doação de órgãos, bem como, por meio da comunicação, de forma clara, aberta, dialógica e acolhedora. Ao procurar compreender a probabilidade do resultado em ser favorável, torna-se maior.

... os significados e respostas vão surgindo através da comunicação entre os familiares e profissionais...(LL04)

Por este foco, pode-se elucidar a importância da atuação do profissional enfermeiro, uma vez que, a Resolução COFEN-240/2000, no art. 26, relata claramente, que 
cabe a esse profissional, prestar adequadas informações ao cliente e família a respeito da assistência de Enfermagem, apresentando possíveis benefícios, riscos e consequências que possam vir a ocorrer.

Em acréscimo ao parágrafo anterior, cita-se a Resolução do COFEN 292/2004, que proclama a necessidade de permanência do doador em UTI, até a retirada dos Órgãos, incumbindo ao enfermeiro, levantar problemas, planejar, executar, coordenar, supervisionar e avaliar os procedimentos de Enfermagem prestados aos doadores de órgãos e tecidos humanos.

Estes dados, rementem a reflexões que vão ao encontro dessa resolução. Dentre os profissionais que atuam na equipe intra-hospitalar, o enfermeiro é o que permanece junto ao paciente por um período maior de tempo. Assim, pode-se dizer que, esse fato, aliado à comunicação que é considerada umas das habilidades do enfermeiro, ressalta a relevância desse profissional na abordagem familiar. Sendo a pessoa recomendada para tal função (MCGOUGH; CHOPEK, 1990), pois isso possibilita a menção, conforme o recorte abaixo:

... há necessidade de melhorar as informações prestadas aos familiares..(LLO2).

Diante desta categoria, anteriormente, citada (03), emergiu as duas seguintes subcategorias.

Subcategoria Analítica 1 - Falta de informação pelo profissional à família referente à possível Morte Encefálica

Compreende-se que a morte pode causar desconforto não só aos familiares, mas também, aos profissionais envolvidos, nesse processo. Tal situação, transcreve uma possível dificuldade de oferecer maiores informações aos familiares, sobre a morte.

... a família fica chocada ao receber a informação do diagnóstico de morte encefálica quando não há esclarecimento prévio sobre a possibilidade de ocorrência... (LLO1)

O critério e o fator determinativo de morte, são questões extremamente, polêmicas e de difícil aceitação (SANTOS; BUENO, 2010). Advém da evolução tecnológica e cultural da sociedade, caracterizado pelo problema crucial do diagnóstico seguro de morte e da interrupção total do tratamento de sustentação da vida residual ou artificial, sendo essencial para os procedimentos de retirada de órgãos vitais.

A família, é o elemento principal para que ocorra, com sucesso, o processo de doação. Deste modo, ela deve receber todas as informações necessárias antes e depois do diagnóstico de morte encefálica. Esse diagnóstico, é avaliado como uma das fontes de maior estresse (CINQUE; BIANCHI, 2010). Isto acaba tornando-se um dos grandes fatores que dificulta a doação de órgãos, conforme pode observar no recorte abaixo:

... acrescenta-se ao sofrimento e a revolta da família, as dúvidas a respeito do que é morte encefálica e o que acontece posteriormente.. Insegurança em doar os órgãos da pessoa viva... (LL03)

Antes de qualquer tentativa de abordagem fami- liar, é importante que se esclareça o diagnóstico de morte encefálica, procurando entender que esse tipo de morte não é simples intercorrência. Por vez, quando a família observa que todos os recursos foram utilizados, isso gera segurança e confiança na atuação profissional.

... a família não é informada do início dos procedimentos de confirmação de morte encefálica e a noticia só é dada depois que o diagnóstico, é constatado. A falta de esclarecimento gera angústia, dor e desespero...(WS02)

O fato é que, lidar com a morte, gera desconforto, tornando-se mais complexo ainda, esse processo, principalmente, em se tratando de morte encefálica, pois, diagnosticar e manter em condições adequadas não é tarefa fácil. É preciso monitorização permanente na UTI, com o objetivo de identificar pacientes com provável evolução para esse tipo de morte (RECH; FILHO, 2007).

A dificuldade de lidar com tal situação, não ocorre somente entre os familiares. Mas, afeta também, os profissionais de saúde (SILVA; SILVA, 2007; ALMEIDA, et al., 2012; ALMEIDA; BUENO; BALDISSERA, 2014). Diante do exposto, estudiosos alertam para a necessidade de um preparo acadêmico, em relação à temática morte (SANTOS; BUENO, 2010).

... as dúvidas a respeito do diagnóstico de morte encefálica podem manter a família em situações de conflito, dificultando a tomada da decisão e a convivência com a decisão de ter doado... (LL03)

\section{Subcategoria Analítica 2 - Falta de informação pelo pro- fissional à família referente aos trâmites pós doação}

Em decorrência dos diversos fatores, já citados, que dificultam o processo, na visão familiar, o pós doação torna-se uma nova barreira que vem como negativo, influenciando na decisão final.

O processo ou o cuidado com o paciente, não termina com a autorização para captação de órgãos. $\mathrm{O}$ tratamento com o corpo do doador merece profunda consideração, já que esse deve ser manipulado com respeito e dignidade.

A burocracia que gira em torno do processo doação/ transplante é considerada um nó crítico no Sistema Nacional de Transplante, pelo fato de reduzir o número de transplantes realizados. A demora para a retirada dos órgãos e a preocupação com a mutilação do corpo causam sofrimento e incômodo aos parentes. Esse atraso na liberação do corpo é relatado como um ponto negativo do processo (ROZA, et al., 2009; RODRIGUES; SATO, 2003). Aqui, apresenta-se achados que vão ao encontro do recorte abaixo:

... o longo tempo, os trâmites e as informações contraditórias no processo de liberação do corpo pelo IML causam transtornos e incomodam os familiares... (LL01)

Além disso, vários fatores são colocados como capazes de dificultar o processo familiar de doação, como complicações com o funeral, pois diante da burocracia, a apropriação do corpo torna-se sem previsão, o que altera consideravelmente, a historicidade do indivíduo e familiar, 
assim como, os hábitos e rituais religiosos de celebração à despedida do familiar, desrespeitando seus costumes e cultura (SIMINOFF et al., 2007).

Por isso, os familiares devem ser, devidamente, informados sobre todos os procedimentos antes e depois da autorização para doação, por meio de uma postura dialógica, crítico-reflexiva, humanizada e emancipatório (BUENO et al., 2014). Possibilitando assim, evitar qualquer desconfiança e desalento sobre a atuação profissional, sobre o destino dos órgãos e referente à integridade do corpo do seu ente querido. Esse relato está expresso nos fragmentos, a seguir:

... as informações sobre como proceder, onde ir e o tempo para liberação do corpo são imprecisas...(LLO1)

Para evitar qualquer eventualidade desagradável em relação a atuação profissional, faz-se necessário preparo educacional efetivo, e eficaz, permitindo habilidade e competência da equipe, nesse sentido. O que pode ser realizado por meio da Educação Permanente nos serviços de saúde, trabalhando no coletivo, as situações limites, evidenciadas na fala de familiares, Nesse estudo, que passaram pela abordagem familiar, assim como, compreender também, em estudos futuros, os nós-críticos que podem ser desvelados juntos dos profissionais envolvidos nesse processo.

\section{Considerações Finais}

Diante de todo processo de doação/transplante por que passa o paciente e os familiares, bem como a atuação dos profissionais nesse impasse, é realmente, de extrema complexidade. Assim, o conflito que gera na família é normal, até que tudo possa ser esclarecido, afetando certamente, os níveis de saúde mental de todos aqueles que estão envolvidos nesse processo. Enquanto isso não ocorre, vai surgir desconforto, insegurança, desconfiança e depois, sentido de ambivalência quanto ao procedimento e a rapidez das decisões, diante das circunstâncias emergenciais da situação. É preciso compreensão e comportamentos adequados tanto de um lado, quanto do outro que lida com essas questões.

Pensando nisso, acredita-se na importância do desenvolvimento do processo educativo ao longo da vida, concernente ao pressuposto da doação e transplante de órgãos e tecidos do ser humano. Isto posto, leva a refletir sobre a necessidade de serviços e profissionais sérios, éticos e comprometidos, multidisciplinares que possam lidar com essas questões, resgatando a humanização, a cidadania, a qualidade do serviço e do cuidado/assistência, a solidariedade e a ética, sobremaneira, tendo em vista, a segurança, o respeito e a responsabilidade tanto para o ser ali inerte, quanto para aquele que sobreviverá, a família e a equipe profissional, da saúde.

Enquanto esse processo educativo se torne ainda incipiente, é preciso despertar principalmente, nos profissionais, a consciência para o processo de doação/transplante que deve ser mais efetiva possível, visando a melhoria desse intento envolvendo paciente, família e comunidade. Os dados apresentados foram extraídos da literatura científica a que propôs-se buscar no presente estudo, a confirmação, a ocorrência do despreparo dos profissionais para atuarem neste processo, frente ao paciente e a família. Assim, esse estudo atendeu aos objetivos traçados, revelando então, a verdadeira realidade encontrada na comunicação científica brasileira, no que tange a atuação dos profissionais que atuam no processo de doação de órgãos na perspectiva da família, tendo em vista os achados evidenciados, fazendo uso da metassíntese qualitativa, no intuito de realizar uma análise problematizadora da literatura em questão.

\section{Referências}

ALMEIDA, E. C. A. et al. Aspectos ético-legais envolvidos no processo de doação/transplante. Arq. Cien. da Saú.

Unipar. v. 16, n. 3 p. 15-27, 2012.

ALMEIDA, E. C. A.; BUENO, S. M. V.; BALDISSERA, V. D. A. A abordagem dialógica para a formação ética do enfermeiro no processo de doação de órgãos. Arq. Cien. da Saú. Unipar. v. 18, n. 1, p. 10-23, 2014.

BARROSO, J. et al. The challenges of Ssarching for and retrieving qualitative studies. West J Nurs Res. v. 25, n. 2, p. 153-78, 2008.

BOUSSO, R. S. O processo de decisão familiar na doação de órgãos do filho: uma teoria substitutiva. Texto Contexto Enferm. v. 17, n. 1, p. 45-54, 2008.

BRYCE, C. L. et al. Do incentives matter: providing benefits to families of organ donors. Am. J. Transplant. v. 5, n. 12, p. 2999-3008, 2005.

BUENO, S. M. V. Tratado de educação preventiva. Ribeirão Preto: FIERP/EERP USP, 2009.

CANTAROVICH, F. Public opinion and organ donation suggestions for overcoming barriers. Ann Transplant. v. 10, p. 22-25, 2005.

CINQUE, V. M.; BIANCHI, E. R. F. Estressores vivenciados pelos familiares no processo de doação de órgãos e tecidos para transplantes. Rev Esc Enf. São Paulo, v. 44, n. 4, p. 996-1002, 2010.

COELHO, J. C. U.; MATIAS, J. E. F.; GODOY, J. L. Atualidades e perspectivas dos transplantes de órgãos. In: URBAN, C. A. Bioética clínica. Rio de Janeiro: Revinter, 2003. p. 449-458.

FREIRE, P. Pedagogia do oprimido. 17. ed. Rio de Janeiro: Paz e Terra, 1987.

GARCIA, V. D. Editorial do registro brasileiro de tansplantes. RBT, v. 17, n. 2, p. 40-55, 2011.

JBI. Reviewers' manual. Adelaide/Austrália: The Joanna Briggs. Istitute. 2008. Disponível em: <http://www. joannabriggs.edu.au/pdf/JBIReviewManual_CiP11449. pdf $>$. Acesso em: 15 jan. 2015.

KIUCHI, T.; TANAKA, K. Liver transplantation from living donos: current status in japan and safty/long-term 
results in the donor. Transplant Proc. v. 35, p. 1172-1173, 2003.

LOPES, A. L. M.; FRACOLLI, L. A. Processos de educação em saúde na cessação do tabagismo: revisão sistemática e metassintese. 2008. ...f. Dissertação

(Mestrado) - Escola de Enfermagem, Universidade de São Paulo - USP, São Paulo, 2008.

MCGGOUGH, E. A; CHOPEK, M. W. The Physician's role as asker in obtaining organ donations. Transplant Proc. v. 22 , p. $267-72,1990$

PELLETIER, M. The organ donor Family members' perception of stressful situations during the organ donation experience. J Adv Nurs. v. 17, n. 1, p. 90-97, 1992.

RECH, T. H.; FILHO, E. M. R. Entrevista familiar e consentimento. Rev Bras Ter Int. v. 19, n. 1, p. 85-89, 2007.

RODRIGUES, A. M.; SATO, E. Entendimento dos médicos intensivistas sobre o processo de doação de córneas. Arq Bras Oftalmol. v. 66, p. 29-32, 2003.

ROZA, B. A. et al. Doação de órgãos e tecidos no Brasil: podemos evoluir? O mundo da Saúde São Paulo, v. 33, n. 1, p. 43-48, 2009.

SANTOS, J. L.; BUENO, S. M.V. Educação para a morte a docentes e discentes de enfermagem: revisão documental da literatura científica. Rev Esc Enf. v. 45, n. 1, p. 272-276, 2010 .

SILVA, A. M.; SILVA, M. J. P. A preparação do graduando de enfermagem para abordar o tema morte e doação de órgãos. Rev. Enferm UERJ. v. 15, n. 4, p. 549-554, 2007.

SIMINOFF, L. et al. The reasons famílies donate organs for transplantation: implications for policy and practice. $\mathbf{J}$ Trauma, v. 62, n. 4, p. 969-978, 2007. 